\title{
Hyperammonemia in a Woman with Late-onset Ornithine Transcarbamylase Deficiency
}

\author{
Yudai Koya ${ }^{1}$, Michihiko Shibata ${ }^{1}$, Michio Senju ${ }^{1}$, Yuichi Honma ${ }^{1}$, Masaaki Hiura ${ }^{1}$, \\ Masahiro Ishii ${ }^{2}$, Shirou Matsumoto ${ }^{3}$ and Masaru Harada ${ }^{1}$
}

\begin{abstract}
:
A 52-year-old woman developed vomiting and disturbance of consciousness after consuming raw fish and sushi on a trip. A blood test showed hyperammonemia $(310 \mu \mathrm{g} / \mathrm{dL})$ with a normal liver function. She fell into a deep coma, and her serum ammonia level increased to $684 \mu \mathrm{g} / \mathrm{dL}$. L-arginine was administered as a diagnostic treatment for urea cycle disorder (UCD) and serum ammonia, and her consciousness levels improved. She was diagnosed with ornithine transcarbamylase deficiency (OTCD) by analyses of plasma amino acids, urinary orotic acid, and the OTC gene mutation. UCD should be considered for patients with hyperammonemia without severe liver function abnormalities.
\end{abstract}

Key words: hyperammonemia, ornithine transcarbamylase deficiency, urea cycle, urea cycle disorder, Larginine, c.119G $>$ A mutation

(Intern Med 58: 937-942, 2019)

(DOI: 10.2169/internalmedicine.1851-18)

\section{Introduction}

Ammonia is produced continuously in the body, mostly in the gut, but also in the kidney and muscle. It readily crosses the blood-brain barrier and exerts toxic effects on the brain at high concentrations (1). Therefore, ammonia is detoxified temporarily into the non-toxic amino acid glutamine. Ammonia produced in the intestine is transported to the portal circulation through the intestinal wall, carried to the liver, and converted to non-toxic urea. This system is called the urea cycle (ornithine cycle), and the liver is primarily responsible for the degradation of ammonia.

Most adult cases of hyperammonemia are complicated by severe liver diseases, such as liver cirrhosis or acute liver failure (2). However, there are some cases without severe liver abnormalities (3-9). Urea cycle disorders (UCDs) are major causes of hyperammonemia. The acute presentation of UCDs must be diagnosed promptly and treated by arginine products or hemodialysis. UCDs may show hyperammonemia refractory to the usual treatments of hepatic encephalo- pathy, easily progressing to coma with potentially fatal outcomes. Ornithine transcarbamylase deficiency (OTCD) is the most common UCD $(10,11)$.

We herein report a woman with OTCD who fell into a coma after travelling and recovered rapidly with the administration of L-arginine.

\section{Case Report}

A 52-year-old woman had suffered from general fatigue and nausea for a few days after consuming raw fish, sushi, and meat while traveling in 2015. She developed vomiting, became incoherent, and was admitted to a local hospital (hospital day 1). She had a history of temporary liver injury and abnormal behavior, using abusive words and throwing nearby objects during hyperemesis gravidarum. She was not a habitual drinker. She had not been exposed to hepatotoxic chemicals or drugs and had no habit of avoiding highprotein foods. Her parent's marriage was not consanguineous. Two of her cousins had died from unknown acute liver failure at the age of 16 , and her daughter had a stillborn

\footnotetext{
${ }^{1}$ Third Department of Internal Medicine, School of Medicine, University of Occupational and Environmental Health, Japan, ${ }^{2}$ Department of Pediatrics, School of Medicine, University of Occupational and Environmental Health, Japan and ${ }^{3}$ Department of Pediatrics, Graduate School of Medical Sciences, Kumamoto University, Japan

Received: July 19, 2018; Accepted: September 12, 2018; Advance Publication by J-STAGE: November 19, 2018

Correspondence to Dr. Yudai Koya, 58yudaikoya@gmail.com
} 


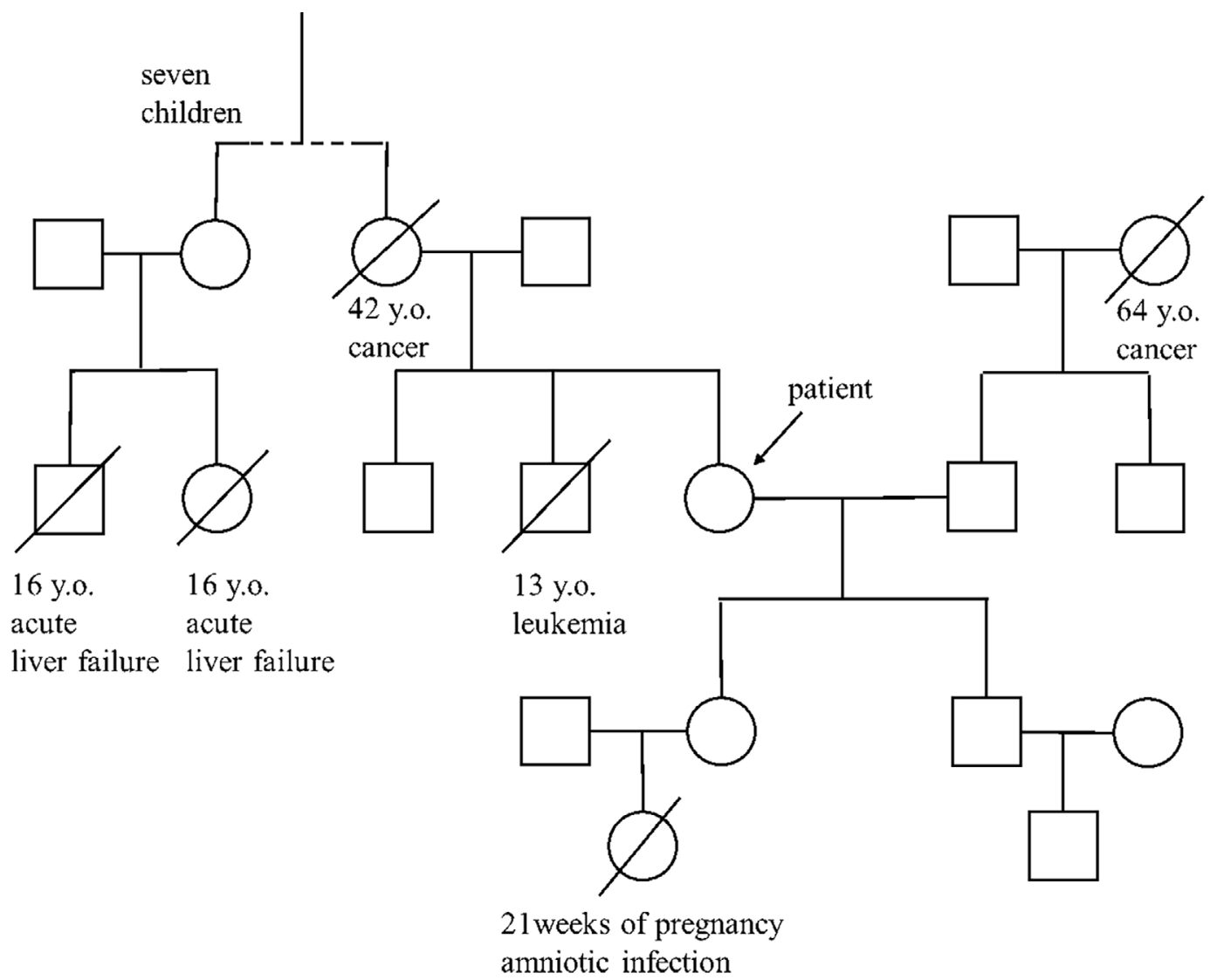

Figure 1. Pedigree of the four-generation family in the present case. An oblique line indicates death. The age and cause of death are indicated below. Two of her cousins died from acute liver failure at the age of 16, and her daughter had a stillborn baby at 21 weeks of pregnancy due to amniotic infection.

baby at 21 weeks of pregnancy due to amniotic infection (Fig. 1).

She was not overweight (body mass index $19.7 \mathrm{~kg} / \mathrm{m}^{2}$ ). Her vital signs were stable. A blood test on admission showed hyperammonemia $(310 \mu \mathrm{g} / \mathrm{dL})$, whereas other data, including her complete blood count, liver and renal function tests, blood glucose, electrolytes, coagulopathy and arterial blood gas findings, were within respective normal ranges (Table). Imaging inspections, including abdominal ultrasound and computed tomography (CT), revealed that both the liver and spleen were normal in size and shape, and there was no evidence of portal hypertension or portosystemic shunt (Fig. 2).

Her consciousness level rapidly worsened, and she fell into a deep coma. Her serum ammonia level increased to $684 \mu \mathrm{g} / \mathrm{dL}$ the next morning (hospital day 2, Fig. 3a). Larginine was administered intravenously as a diagnostic treatment, as typical hepatic hyperammonemia was unlikely, and UCDs were considered to be the most likely cause. She was transferred to our hospital for the further evaluation and treatment on the same day. Her serum ammonia level at the time of admission to our hospital had decreased to $69 \mu \mathrm{g} / \mathrm{dL}$ after the intravenous administration of L-arginine. Her consciousness level gradually recovered, and her Glasgow Coma Scale score was 10/15 (12). A neurologic examination revealed the presence of a light reflex, no pathological re- flexes and no symptoms of meningeal irritation. Viral hepatitis markers and antinuclear antibodies were all negative (Table). Although a triphasic wave was transiently observed on electroencephalography, brain CT and magnetic resonance imaging revealed no pathological findings. A cerebrospinal fluid examination revealed normal findings.

Because the serum ammonia levels responded quickly and dramatically to intravenous L-arginine, we strongly suspected UCD. We continued to administer L-arginine intravenously at $30 \mathrm{~g} /$ day, along with a glucose-electrolyte solution with vitamin B1, B6 and B12. In addition, $39 \mathrm{~g} /$ day of lactulose and 3,000 mg/day of levocarnitine were administered via a nasogastric tube (Fig. 3a). Her consciousness level became clear on hospital day 5 , so we introduced a proteinrestricted diet $(0.7 \mathrm{~g} / \mathrm{kg} /$ day $)$ and began the oral administration of $600 \mathrm{mg} /$ day ascorbic acid (vitamin C) and $30 \mathrm{mg}$ / day ubidecarenone (coenzyme Q10). An analysis of plasma amino acids, taken before the administration of L-arginine, revealed increased levels of glutamine and lysine and decreased citrulline levels. Furthermore, the urinary orotic acid excretion was also markedly increased (Table). Therefore, we made a definitive diagnosis of OTCD.

Because the serum ammonia level was normalized on hospital day 17, levocarnitine was tapered and discontinued, and oral L-arginine was tapered to $6 \mathrm{~g} / \mathrm{day}$. The patient was discharged on hospital day 27 while continuing medications 
Table. Laboratory Findings on Admission.

\begin{tabular}{|c|c|c|c|c|}
\hline \multicolumn{2}{|c|}{ Hematology } & \multicolumn{3}{|l|}{ Coagulation } \\
\hline WBC & $11,200 / \mu \mathrm{L}$ & PT\% & $75 \%$ & \\
\hline Neutro & $69.1 \%$ & PT-INR & 1.13 & \\
\hline $\mathrm{RBC}$ & $480 \times 10^{4} / \mu \mathrm{L}$ & APTT & $34.7 \mathrm{sec}$ & \\
\hline $\mathrm{Hb}$ & $14.3 \mathrm{~g} / \mathrm{dL}$ & & & \\
\hline $\mathrm{Ht}$ & $41.2 \%$ & Virus markers & & \\
\hline \multirow[t]{2}{*}{ Plt } & $36.9 \times 10^{4} / \mu \mathrm{L}$ & HBsAg & $(-)$ & \\
\hline & & $\mathrm{HBcAb}$ & $(-)$ & \\
\hline \multicolumn{2}{|c|}{ Biochemistry } & $\mathrm{HCVAb}$ & $(-)$ & \\
\hline $\mathrm{TP}$ & $7.4 \mathrm{~g} / \mathrm{dL}$ & & & \\
\hline $\mathrm{Alb}$ & $4.2 \mathrm{~g} / \mathrm{dL}$ & \multicolumn{3}{|c|}{ Arterial blood gas (room air) } \\
\hline T-bil & $2.3 \mathrm{mg} / \mathrm{dL}$ & $\mathrm{pH}$ & 7.49 & \\
\hline D-bil & $0.5 \mathrm{mg} / \mathrm{dL}$ & $\mathrm{PaCO}_{2}$ & $34 \mathrm{mmHg}$ & \\
\hline AST & $16 \mathrm{IU} / \mathrm{L}$ & $\mathrm{PaO}_{2}$ & $141 \mathrm{mmHg}$ & \\
\hline ALT & $20 \mathrm{IU} / \mathrm{L}$ & $\mathrm{BE}$ & $2.9 \mathrm{mmol} / \mathrm{L}$ & \\
\hline LDH & $150 \mathrm{IU} / \mathrm{L}$ & $\mathrm{HCO}_{3}$ & $25.9 \mathrm{mmol} / \mathrm{L}$ & \\
\hline ALP & $193 \mathrm{IU} / \mathrm{L}$ & & & \\
\hline GGT & 12 IU/L & \multicolumn{2}{|c|}{ Plasma amino acids } & (Normal values) \\
\hline BUN & $12.1 \mathrm{mg} / \mathrm{dL}$ & Glutamine & $902 \mathrm{nmol} / \mathrm{mL}$ & $(422-703)$ \\
\hline Cre & $0.45 \mathrm{mg} / \mathrm{dL}$ & Citrulline & $16.3 \mathrm{nmol} / \mathrm{mL}$ & $(17.1-42.6)$ \\
\hline $\mathrm{Na}$ & $138 \mathrm{mEq} / \mathrm{L}$ & Lysine & $295 \mathrm{nmol} / \mathrm{mL}$ & $(108-242)$ \\
\hline $\mathrm{K}$ & $3.8 \mathrm{mEq} / \mathrm{L}$ & & & \\
\hline $\mathrm{Cl}$ & $104 \mathrm{mEq} / \mathrm{L}$ & \multicolumn{3}{|c|}{ Urine organic acids } \\
\hline FPG & $136 \mathrm{mg} / \mathrm{dL}$ & Orotic acid & $\uparrow$ & \\
\hline $\mathrm{NH}_{3}$ & $310 \mu \mathrm{g} / \mathrm{dL}$ & Uracil & $\uparrow$ & \\
\hline \multicolumn{5}{|l|}{ Serology } \\
\hline CRP & \multicolumn{4}{|l|}{$0.08 \mathrm{mg} / \mathrm{dL}$} \\
\hline ANA & \multicolumn{4}{|l|}{$(-)$} \\
\hline \multicolumn{5}{|c|}{$\begin{array}{l}\text { WBC: white blood cell, Neutro: neurtophil, RBC: red blood cell, Hb: hemoglobin, Ht: hematocrit, } \\
\text { Plt: platelet count, TP: total protein, Alb: albumin, T-bil: total bilirubin, D-bil: direct bilirubin, AST: } \\
\text { aspartate aminotransferase, ALT: alanine aminotransferase, LDH: lactate dehydrogenase, ALP: al- } \\
\text { kaline phosphatase, GGT: gamma glutamyl transpeptidase, BUN: blood urea nitrogen, Cre: creati- } \\
\text { nine, FPG: fasting plasma glucose, } \mathrm{NH}_{3} \text { : ammonia, ANA: antinuclear antibody, CRP: C-reactive } \\
\text { protein, PT: prothrombin time, APTT: activated partial thromboplastin time, HBsAg: hepatitis B } \\
\text { surface antigen, HBcAb: hepatitis B core antibody, HCVAb: hepatitis C antibody, BE: base excess }\end{array}$} \\
\hline
\end{tabular}

(L-arginine, vitamin $\mathrm{B}_{1}$, vitamin $\mathrm{B}_{6}$, vitamin $\mathrm{B}_{12}$, vitamin $\mathrm{C}$ and ubidecarenone) and a low-protein diet. After informed consent was obtained, a genomic analysis of the OTC gene was performed. The analysis revealed Arg40His (c.119G> A), a heterozygous mutation of the OTC gene (Fig. 3b).

\section{Discussion}

Hyperammonemia usually occurs as a consequence of severe liver diseases, such as cirrhosis or acute liver failure. However, other unusual nonhepatic causes should also be considered, such as an occult inborn error of metabolism, intake of certain drugs (e.g., anticonvulsants, 5-fluouracil, ribavirin), infection by urea-producing bacteria, hematooncological disorders and gastrointestinal bleeding (3-9).

Inborn errors of metabolism include UCDs, organic acidurias, defects in fatty acid oxidation causing carnitine deficiency, dibasic aminoaciduria and defects in pyruvate metabolism, and UCD is the most common among them (3).
UCD has an estimated incidence of 1 in every 8,000-44,000 births (13-15). OTCD, which is caused by mutations in OTC, is a common UCD and occurs in 1 of every 80,000 births in Japan (16). The OTC gene is expressed in an Xlinked dominant manner $(13,17)$, and the gene product (OTC) is expressed in the mitochondrial matrix of the liver and small intestine (18). The c.119G $>$ A mutation detected in the present case is identified in a minority of case reports regarding late onset OTCD, and Nishiyori et al. found that such patients were born within a limited area of the northern part of Kyushu Island in southern Japan $(19,20)$. The present patient was born and raised in the same area. This mutation is usually associated with a mild phenotype, and almost all patients with this mutation who develop late-onset OTCD are men. An extremely rare case of a woman with this mutation who developed late-onset OTCD was previously reported, although she was 13 years of age (20). To our knowledge, this is the first report describing a woman with the c.119G $>$ A mutation who developed hyperammone- 


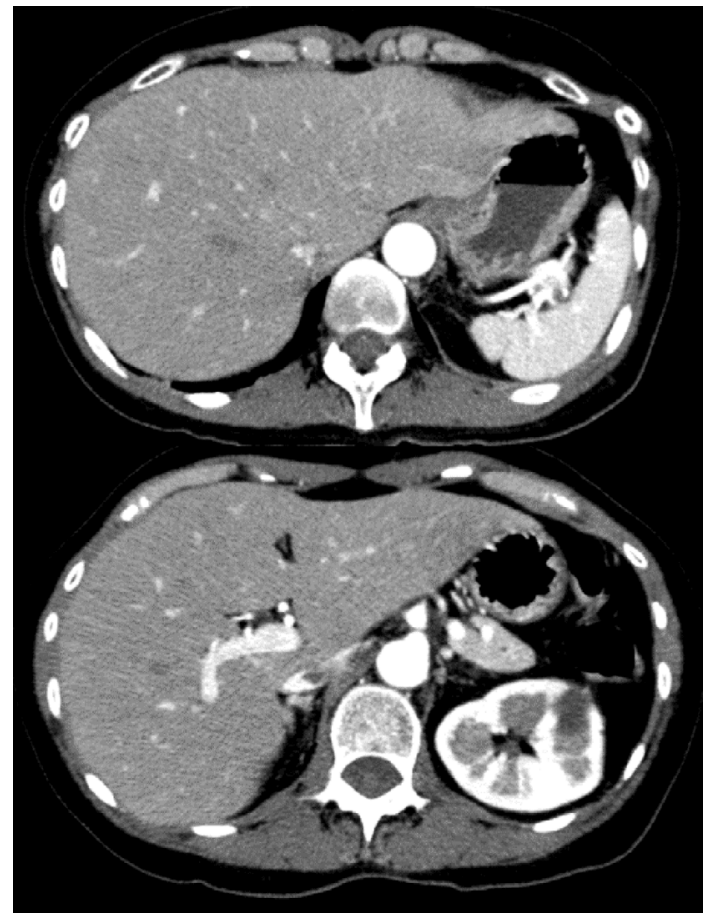

Figure 2. Abdominal contrast enhanced CT on admission. Both the liver and spleen were normal in size and shape. There were no findings indicating portal hypertension or portosystemic shunt.

mia in middle age. We should recognize that middle-aged women with the c.119G $>$ A mutation can present with hyperammonemia, and the outcome can be fatal if not properly managed. Genetic counseling was performed for the patient's daughter, and a genomic analysis is currently being performed.

Although commonly diagnosed in neonates, patients with OTCD can present at any age with hyperammonemic crisis owing to environmental stressors $(1,15)$. The present patient first became symptomatic during pregnancy in her $20 \mathrm{~s}$, and she was diagnosed with OTCD in middle age. In most hyperammonemic episodes, patients typically present with a loss of appetite, vomiting, lethargy and abnormal behaviors associated with hallucinations, sleep disorders, ataxia and seizures. These symptoms are frequently triggered by highprotein diets and acute stresses or illness, such as sepsis, surgery, anesthesia, pregnancy, trauma or drugs (15). In the present case, the increased intake of protein by eating raw fish, sushi and meat during her travels was definitely responsible for the cascade of events leading to her hyperammonemia. She rarely ate meat in her everyday life, being almost completely vegetarian. Her dietary preference for vegetables should be considered an important clinical clue, since voluntary protein avoidance is a characteristic eating behavior that UCD patients adopt in order to avoid postprandial headache or drowsiness (21).

Two of the present patient's cousins died from acute liver failure at the age of 16. They might also have had OTCD that was misdiagnosed as ordinary hepatic encephalopathy. In UCD patients, serum ammonia levels may increase by the intake of branched-chain amino acid products that are usually used for hepatic hyperammonemia, as these products can precipitate an excessive nitrogen load. However, it is difficult to differentiate UCD from typical hepatic hyperammonemia, especially in cases of adult-onset acute encephalopathy, because hepatomegaly and a moderate increase in serum aminotransferases are common during episodes of acute hyperammonemia $(3,10,18,22)$. High-dose administration of anticonvulsants during acute episodes of hyperammonemia should be avoided, as these drugs can actually increase serum ammonia levels (7). Acute hyperammonemia in UCD patients may progress rapidly, as in the present case, and can be fatal. Therefore, they must be diagnosed correctly based on a review of the patient's history and laboratory and imaging findings. If typical acute liver failure is unlikely, analyses of serum and urinary amino acids should be performed in order to achieve a correct diagnosis and begin appropriate treatment. However, analyses of amino acids can take a few days, so the administration of L-arginine may be useful as a diagnostic treatment in a clinical setting, as was the case with our patient. Given that our patient a good response to L-arginine, UCD was strongly suspected.

Arginine is essential for protein synthesis, and its deficiency may lead to hypercatabolism, resulting in hyperammonemia. The administration of arginine in patients without a definitive diagnosis of the specific type of UCD is very important, as demonstrated by the current case $(14,23)$. However, arginine is contraindicated in neonates with arginase deficiency because it accelerates hyperargininemia. Citrulline is also useful for reducing plasma ammonia levels in OTCD patients, but it is not approved as a therapeutic drug and is available only as a supplement in Japan. Sodium benzoate and sodium phenylbutyrate are also useful, using an alternative pathway that diverts nitrogen from the urea cycle to other routes of excretion by the kidneys (23). Although sodium benzoate has not yet been approved as a therapeutic drug in Japan, phenylbutyrate was approved in 2013. Carnitine is also useful for reducing plasma ammonia levels in acute UCD patients by activating carbamoylphosphate synthase 1, which catalyzes the synthesis of carbamoylphosphate from $\mathrm{N}$-acetyl glutamate and bicarbonate $(3,24,25)$.

Hemodialysis is another useful treatment for removing ammonia from blood; however, there are no standard criteria for initiating hemodialysis. Hemodialysis is recommended in order to avoid central nervous system after-effects when peak ammonia levels exceed $300 \mu \mathrm{g} / \mathrm{dL}$ (26). We did not perform hemodialysis in this case because the symptoms rapidly improved after the administration of L-arginine.

In conclusion, OTCD may be predicted by hypocitrullinemia discovered via neonatal mass screening in Japan, but patients who present with hyperammonemia after the neonatal period may not be identified. They can develop acute hyperammonemic encephalopathy incidentally by various triggers in adulthood. When we encounter patients with unusual hyperammonemia, OTCD should be considered so that fatal 


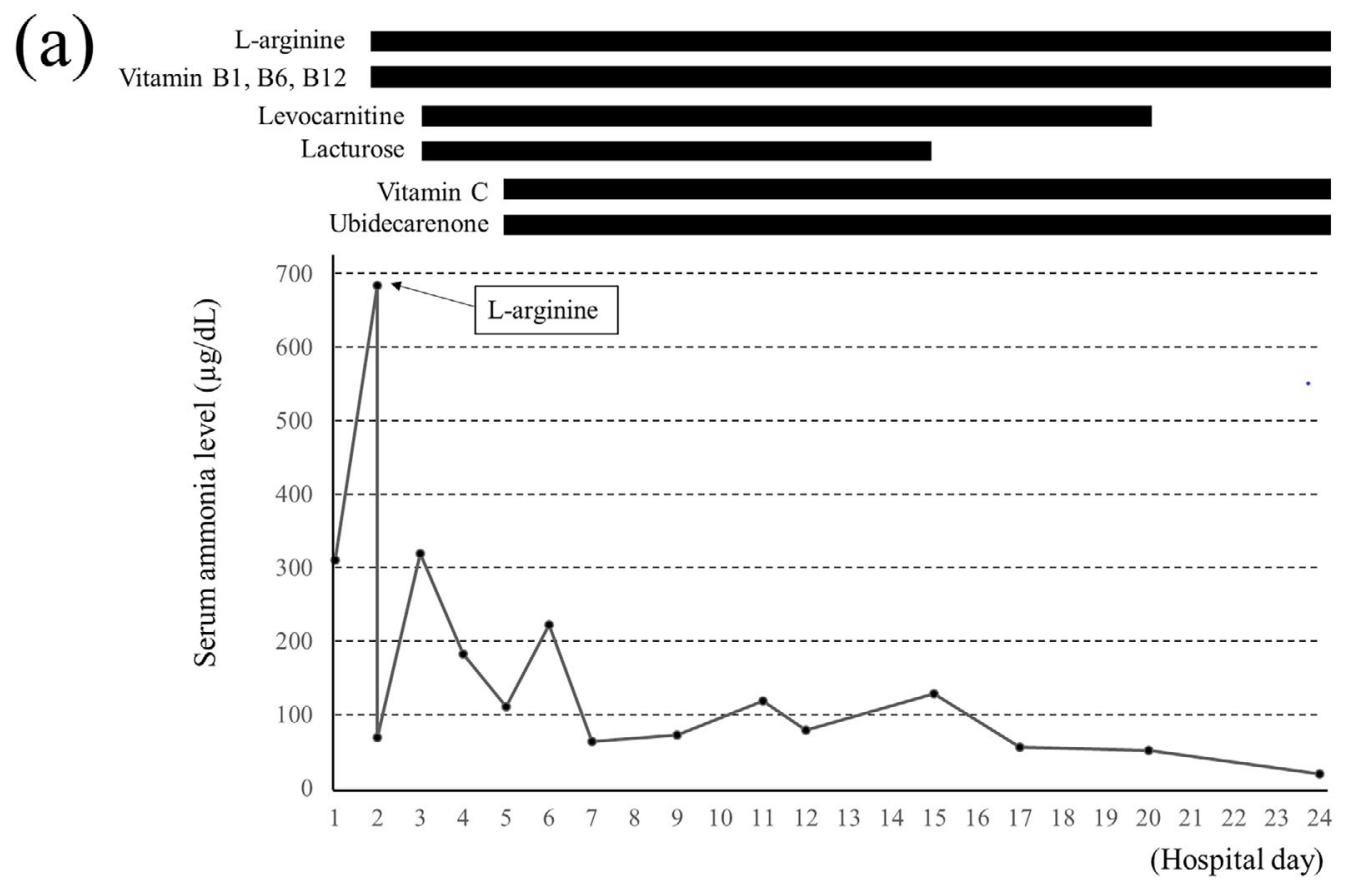

(b)
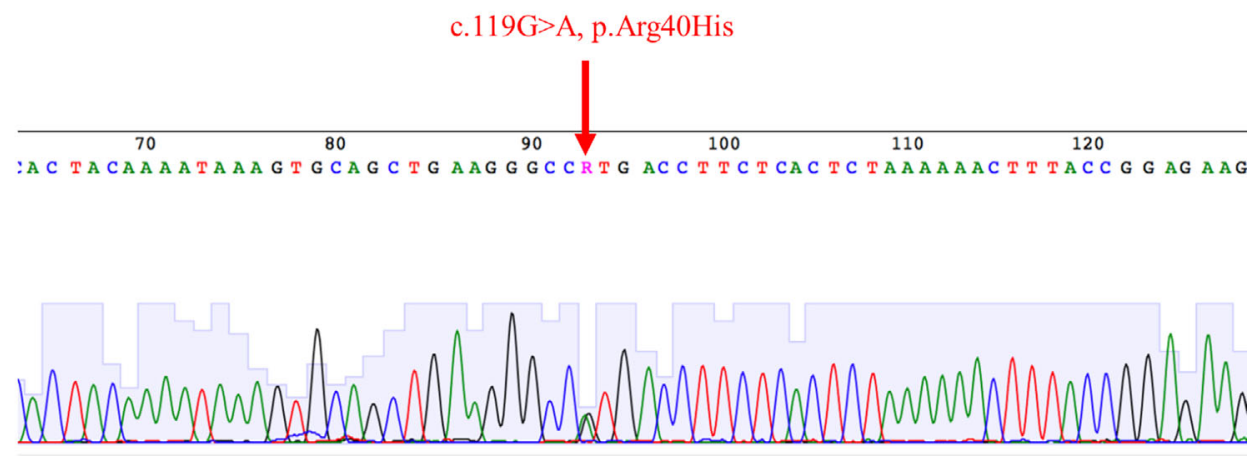

Figure 3. The clinical course of the present case and results of a genomic analysis of the OTC gene. (a) The serum ammonia level worsened rapidly from hospital day 1 to day 2 and improved rapidly after the administration of $\mathrm{L}$-arginine on day 2 . Her consciousness recovered on hospital day 5. (b) A genomic analysis revealed an Arg40His (c.119G>A) heterozygous mutation in the OTC gene.

outcomes can be avoided by the prompt diagnosis and adequate treatment.

The authors state that they have no Conflict of Interest (COI).

\section{Financial Support}

This research was supported by AMED under Grant Number JP17ek0109276.

\section{References}

1. Walker V. Ammonia toxicity and its prevention in inherited defects of the urea cycle. Diabetes Obes Metab 11: 823-835, 2009.

2. Walker V. Severe hyperammonemia in adults not explained by liver disease. Ann Clin Biochem 49: 1-15, 2012.

3. Treem WR. Inherited and acquired syndromes of hyperammonemia and encephalopathy in children. Semin Liver Dis 14: 236-258, 1994.

4. De Jonghe B, Janier V, Abderrahim N, Hillion D, Lacherade JC, Outin H. Urinary tract infection and coma. Lancet 360: 996, 2002.
5. Lora-Tamayo J, Palom X, Sarrá J, et al. Multiple myeloma and hyperammonemic encephalopathy: review of 27 cases. Clin Lymphoma Myeloma 8: 363-369, 2008.

6. Yeh $\mathrm{KH}$, Cheng AL. High dose 5-fluorouracil infusional therapy is associated with hyperammonemia, lactic acidosis and encephalopathy. Br J Cancer 75: 464-465, 1997.

7. Wadzinski J, Franks R, Roane D, Bayard M. Valporate-associated hyperammonemic encephalopathy. J Am Board Fam Med 20: 499502, 2007.

8. Bertrand $\mathrm{P}$, Faro A, Cantwell P, Tzakis A. Intravenous ribavirin and hyperammonemia in an immunocompromised patient infected with adenovirus. Pharmacotherapy 20: 1216-1220, 2000.

9. Olde Damink SW, Dejong CH, Deutz NE, van Berlo CL, Soeters PB. Upper gastrointestinal bleeding: an ammoniagenic and catabolic event due to the total absence of isoleucine in the hemoglobin molecule. Med Hypotheses 52: 515-519, 1999.

10. Burton BK. Urea cycle disorders. Clin Liver Dis 4: 815-830, 2000.

11. Kleppe S, Mian A, Lee B. Urea cycle disorders. Curr Treat Opt Neurol 5: 309-319, 2003.

12. Teasdale G, Jennett B. Assessment of coma and impaired consciousness. A practical scale. Lancet 2: 81-84, 1974. 
13. Yamaguchi S, Brailey LL, Morizono $H$, Bale AE, Tuchman M. Mutations and polymorphisms in the human ornithine transcarbamylase (OTC) gene. Hum Mutat 27: 626-632, 2006.

14. Wilcken B. Problems in the management of urea cycle disorders. Mol Genet Metab 81: 86-91, 2004.

15. Brusilow SW, Horwich AL. Urea cycle enzymes. In: The metabolic and molecular basis of inherited disease. 8th ed. Scriver CR, Beaudet AL, Sly WS, et al., Eds. McGraw-Hill, New York, 2001: 1909-1963.

16. Nagata N, Matsuda I, Oyanagi K. Estimated frequency of urea cycle enzymopathies in Japan. Am J Med Genet 39: 228-229, 1991.

17. Arranz JA, Riudor E, Marco-Martin C, Rubio V. Estimation of the total number of disease-causing mutations in ornithine transcarbamylase (OTC) deficiency. Value of the OTC structure in predicting a mutation pathogenic potential. J Inherit Metab Dis 30: 217-226, 2007.

18. Brusilow SW, Maestri NE. Urea cycle disorders: diagnosis, pathophysiology and therapy. Adv Pediatr 43: 127-170, 1996.

19. Nishiyori A, Yoshino M, Kato $\mathrm{H}$, et al. The $\mathrm{R} 40 \mathrm{H}$ mutation in a late onset type of human ornithine transcarbamylase deficiency in male patients. Hum Genet 99: 171-176, 1997.

20. Pinner JR, Freckmann ML, Kirk EP, Yoshino M. Female heterozygotes for the hypomorphic $\mathrm{R} 40 \mathrm{H}$ mutation can have ornithine transcarbamylase deficiency and present in early adolescence: a case report and review of the literature. J Med Case Rep 4: 361,
2010.

21. Rowe PC, Newman SL, Brusilow SW. Natural history of symptomatic partial ornithine transcarbamylase deficiency. N Engl J Med 314: 541-547, 1986.

22. Tokatli A, Coskan E, Ozalip I. Fifteen years' experience with 212 hyperammonemic cases at a metabolic unit. J Inherit Metab Dis 14: 698-706, 1991.

23. Brusilow SW, Valle DL, Batshaw M. New pathways of nitrogen excretion in inborn errors of urea synthesis. Lancet 2: 452-454, 1979.

24. Malaguarnera M, Pristone G, Astuto M, et al. L-carnitine in the treatment of mild or moderate hepatic encephalopathy. Dig Dis 21: 271-275, 2003.

25. Ohtani Y, Ohyanagi K, Yamamoto S, Matsuda I. Secondary carnitine deficiency in hyperammonemic attacks of ornithine transcarbamylase deficiency. J Pediatr 112: 409-414, 1988.

26. Kido J, Nakamura K, Mitsubuchi H, et al. Long-term outcome and intervention of urea cycle disorders in Japan. J Inherit Metab Dis 35: 777-785, 2012.

The Internal Medicine is an Open Access journal distributed under the Creative Commons Attribution-NonCommercial-NoDerivatives 4.0 International License. To view the details of this license, please visit (https://creativecommons.org/licenses/ by-nc-nd/4.0/).

(C) 2019 The Japanese Society of Internal Medicine Intern Med 58: 937-942, 2019 